Research Article

\title{
Shaking Table Test on the Seismic Responses of a Slope Reinforced by Prestressed Anchor Cables and Double-Row Antisliding Piles
}

\author{
Zuo-ju Wu $\mathbb{D}^{1},{ }^{1}$ Zhi-jia Wang $\mathbb{D},{ }^{2}$ Jun-wei Bi $\mathbb{D}^{3},{ }^{3}$ Xiao Fu $\mathbb{D}^{4},{ }^{4}$ and Yong Yao $\mathbb{D}^{1}$ \\ ${ }^{1}$ School of Civil Engineering and Architecture, Southwest University of Science and Technology, Mianyang, \\ Sichuan 621010, China \\ ${ }^{2}$ College of Civil Engineering and Architecture, Hainan University, Haikou, Hainan 570228, China \\ ${ }^{3}$ College of Civil Engineering, Tongji University, Shanghai 200092, China \\ ${ }^{4}$ School of Civil Engineering, Southwest Jiaotong University, Chengdu, Sichuan 611756, China \\ Correspondence should be addressed to Zuo-ju Wu; 706805410@qq.com
}

Received 3 April 2021; Accepted 4 May 2021; Published 11 May 2021

Academic Editor: Honglue Qu

Copyright (C) 2021 Zuo-ju Wu et al. This is an open access article distributed under the Creative Commons Attribution License, which permits unrestricted use, distribution, and reproduction in any medium, provided the original work is properly cited.

\begin{abstract}
The combined retaining structure has gradually received considerable attention in the slope engineering, due to its good reinforcement effects. However, most of the published research studies were focused on the seismic responses of the single-formal supporting structure only. The investigations of dynamic responses of the combined retaining structures are scarce, and the current seismic design is conducted mainly based on experiences. In this work, a series of large-scale shaking table tests were conducted to investigate the seismic responses of the combined retaining structures (i.e., prestressed anchor cables and doublerow antisliding piles) and the reinforced slope under seismic excitations, including amplification effect of internal and surface acceleration of the reinforced slope, distribution and change of prestress of the anchor cable, dynamic response of soil pressure behind the antislide pile, and horizontal displacement of the reinforced slope surface. Test results show that, supported by the reinforcement of composite support system, the slope with the multilayer weak sliding surface can experience strong ground motion of $0.9 \mathrm{~g}$. The load of the antisliding pile has reached $80 \%$ of its bearing capacity, and the load of the anchor cable has reached $75.0 \%$ of its bearing capacity. When the seismic intensity reaches $0.5 \mathrm{~g}$, the slope surface has an obvious downward trend, which will make the corresponding soil pressure suddenly increase after the antislide pile. At the potential sliding zone, the axial force of the anchor cable will increase suddenly under the action of earthquake; after the earthquake, the initial prestress of the anchor cable will be lost, with the loss range of $17.0 \% \sim 23.0 \%$. These test results would provide an important reference for the further study of the seismic performance of such composite support structure.
\end{abstract}

\section{Introduction}

There are many mountains in Southwest China, so there are many slopes. Particularly, most slope projects in Sichuan Province are located in the areas with high seismic intensity. When strong earthquakes occur, these supporting structures (such as anchor cables and antisliding piles) are often damaged [1-3]. Therefore, the seismic research of the slopesupporting structure is of great significance.

As an important mean to study the seismic performance of supporting structures, the shaking table test has been developing rapidly in the past decade. Lai et al. [4] conducted shaking table tests to research the seismic responses of a slope reinforced by double-row antisliding piles, which indicates that the double-row antisliding piles could effectively resist the combination of tension and shear during earthquake. Jiang et al. [5] performed a series of shaking table model tests of the slope supported by anchor cables to deeply study the responses and characteristics of the reinforced slope under earthquake action. Ye et al. [6] investigated the seismic behavior of a slope reinforced by prestressed anchor cables through the shaking table test, in 
which the antislip mechanism of the prestressed anchor cables is well analyzed. Lin et al. [7] conducted experimental and numerical investigations and researched the seismic behavior of an anchoring frame beam under earthquakes. Through model tests, Zheng et al. [8] investigated the seismic-induced damage and deformation patterns of a rock slope reinforced by prestressed cables. Xu et al. [9] conducted a shaking table test to determine the load transfer mechanism and dynamic response characteristics of a slope supported by adaptive anchor cables. Ma et al. [10] used the shaking table test to study the distribution and variation of the dynamic soil pressures acting on supporting structures, including the antisliding pile and the prestressed anchor slab-pile wall. Through a series of shaking table tests, Ding et al. [11] investigated the seismic behavior and performance of the slopes reinforced by concrete-canvas and composite reinforcement. Zhou et al. [12] analyzed the seismic damages of road slopes in Wenchuan earthquake and pointed out that the prestressed anchor cable and antisliding pile have good earthquake resistance performance. Currently, the combined retaining structures are more and more widely applied, especially for large-scale slope and landslide projects. Lin et al. [13] performed shaking table tests and investigated the dynamic responses of a slope which is reinforced by prestressed anchor cables and single-row antisliding piles. More recently, Fan et al. [14] conducted experimental investigations to study the dynamic behavior of a slope reinforced by double-row antisliding piles and prestressed anchor cables under Wenchuan seismic excitations.

The above studies mainly focus on the seismic response of the single-formal support structure. However, the dynamic response of the slope reinforced by the composite support structure under earthquake action is very limited. Moreover, investigations related to the seismic responses of the slope reinforced by prestressed anchor cables and double-row antisliding piles are rather scarce, and the corresponding design method for such combined retaining structure is still unclear. Therefore, further in-depth study on the dynamic responses of prestressed anchor cables and double-row antisliding piles under the earthquake loadings must be available to improve the current seismic design.

To address these issues, a series of large-scale shaking table tests were conducted to investigate the seismic responses of a slope reinforced by prestressed anchor cables and double-row antisliding piles. Some meaningful conclusions and recommendations are obtained based on the analysis of test results.

\section{Engineering Background}

Figure 1 shows the prototype slope that is located in Sichuan, China. The height and width of the slope are about $150.00 \mathrm{~m}$ and $325.00 \mathrm{~m}$, respectively, and the elevation of the slope toe is $606.00 \mathrm{~m}$. A typical cross section for the shaking table test is selected, as shown in Figure 2. According to the site exploration, the slip bed of the prototype slope mainly formed in intact celadon shale, and the sliding mass mainly consists of the highly weathered shale and Quaternary alluvial deposit. There are two slip surfaces inside the slope,

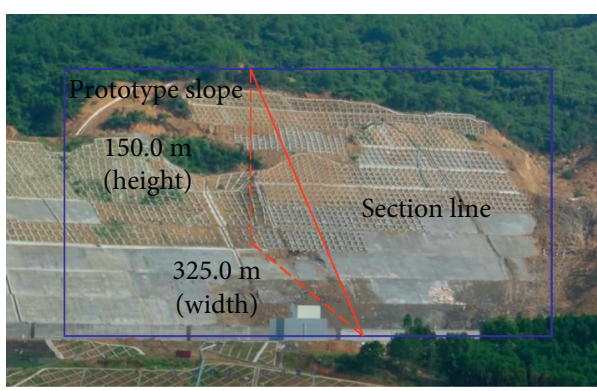

FIGURE 1: Overlook of the prototype slope.

which the potential sliding zones consist of the silty clay with minor gravels. The parameters of the prototype slope are listed in Table 1. In reference to Seismic Ground Motion Parameters Zonation Map of China [15], the seismic design intensity of the prototype site is 7.00 . Therefore, taking consideration of the significance of the prototype slope, the effects of seismic loadings should not be neglected. According to the results of stability analyses, the safety factor of the prototype slope under earthquakes is 1.03 , and the value of which under the pseudostatic conditions is 0.90 . The peak ground acceleration and seismic influence coefficient in the horizontal direction are $0.15 \mathrm{~g}$ and 0.24 , respectively. The calculations show that the residual sliding force of prototype slopes is extremely large; thus, the original design of singlerow antisliding piles and prestressed anchor cables could not meet the needs of stability. Therefore, the slope is designed to be reinforced by prestressed anchor cables and double-row antisliding piles.

\section{Shaking Table Tests}

3.1. Shaking Table Device. The shaking table facility used for the tests allows input of three directions of earthquake records with independent control. The shaking table has 6 degrees of freedom, including 3 degrees of translation and 3 degrees of rotation, and the dimensions of which are $6.0 \mathrm{~m}$ by $6.0 \mathrm{~m}$. At full load, the maximum acceleration could reach $1.0 \mathrm{~g}$ in the horizontal direction and $0.8 \mathrm{~g}$ in the vertical direction. The maximum displacements of the shaking table in the horizontal and vertical direction are $\pm 150.0 \mathrm{~mm}$ and $\pm 100.0 \mathrm{~mm}$, respectively, and the loading frequency range of which is $0.1 \mathrm{~Hz} \sim 80.0 \mathrm{~Hz}$. Additionally, a data acquisition system with 128 channels is adopted, which the maximum error can be controlled within $5.0 \%$.

3.2. Similitude Law. According to the scaling laws, three controlling parameters were selected, which are the dimension $L$, density $\rho$, and acceleration $a$, respectively. Limited by the dimensions and bearing capacity of the shaking table facility, the similar constants of dimension $\left(C_{L}\right)$, density $\left(C_{\rho}\right)$, and acceleration $\left(C_{a}\right)$ were set to be $C_{L}=100.0, C_{\rho}=1.0$, and $C_{a}=1.0$ for this shaking table test, leading to the model slope height of $200.0 \mathrm{~cm}$. Based on the Buckingham $\pi$ theorem [16], the similarity ratios of other parameters for this model test could be obtained, as 


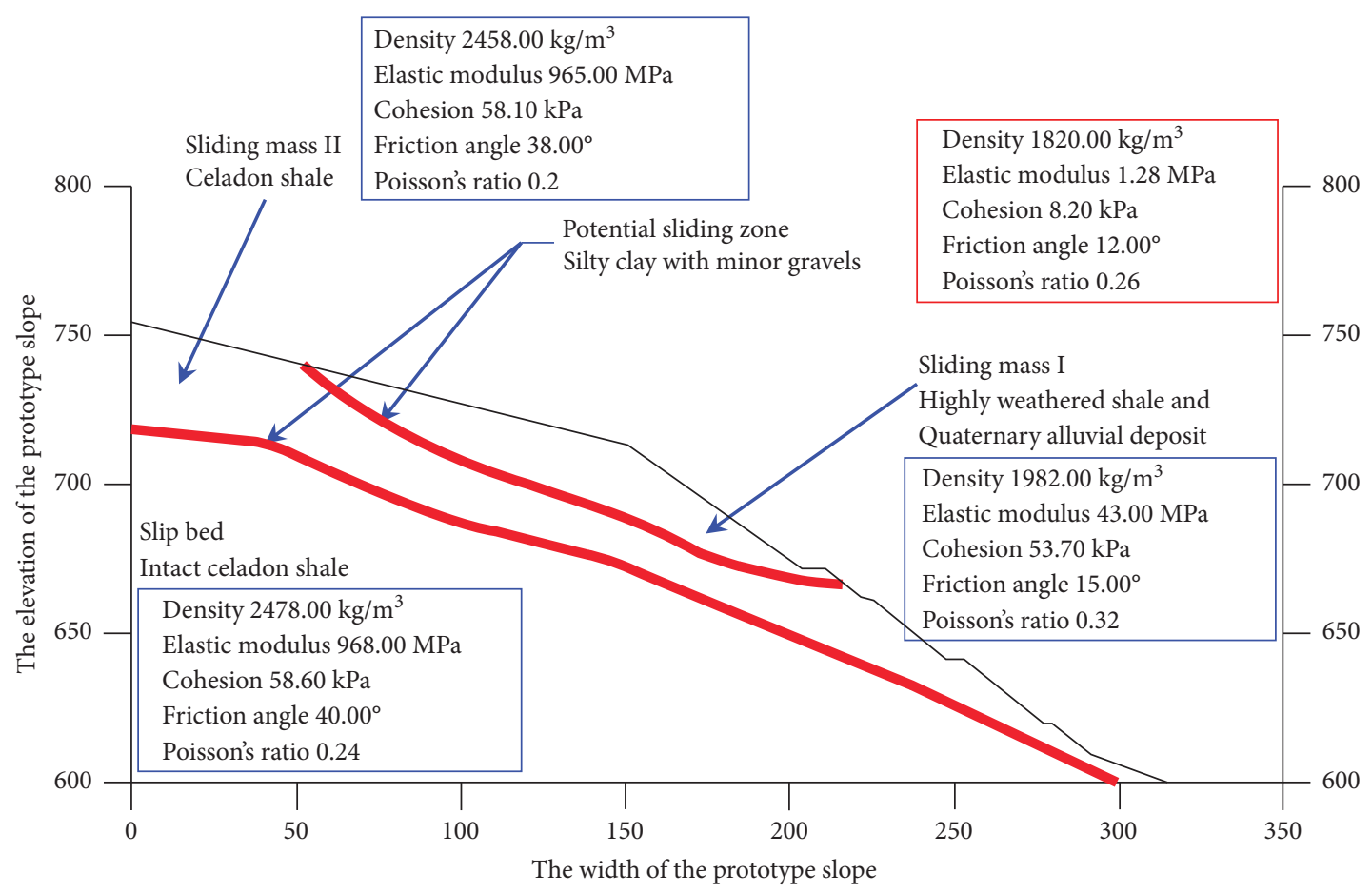

FIgURE 2: The typical section of the prototype slope.

TABLE 1: Material parameters for the prototype slope.

\begin{tabular}{lccccc}
\hline Components & Density $\rho\left(\mathrm{kg} / \mathrm{m}^{3}\right)$ & Elastic modulus $E(\mathrm{MPa})$ & Cohesion $c(\mathrm{kPa})$ & Friction angle $\left(^{\circ}\right)$ & Poisson's ratio $\mu$ \\
\hline Slide bed & 2478.00 & 968.00 & 58.60 & 40.00 & 0.24 \\
Sliding mass II & 2458.00 & 965.00 & 58.10 & 38.00 & 0.25 \\
Sliding mass I & 1982.00 & 43.00 & 53.70 & 15.00 & 0.32 \\
Potential sliding zone & 1820.00 & 1.28 & 8.20 & 12.00 & 0.26 \\
\hline
\end{tabular}

illustrated in Table 2, and the detailed derivation of which could be found in Ref. [17].

3.3. Test Model. The slope model was placed in a rigid box container with waterproof treatment which fixed on the shaking table, and the dimensions of the box are $325.0 \mathrm{~cm} \times 150.0 \mathrm{~cm} \times 250.0 \mathrm{~cm}$ (length $\times$ width $\times$ height), as shown in Figure 3. The slope model was built layer by layer, in which the height of each layer is $20.0 \mathrm{~cm}$. Based on the required thickness and density of each layer, similar materials with a certain quality would be placed into the model box and then compacted to the desired thickness. After each layer was compacted, the cutting ring method was applied to ensure whether the unit weight meets the requirements or not. For the potential sliding zones, the similar materials were obtained from the prototype slope and remodeled for the shaking table tests. After the test model was built, the slope model is saturated through the pipes preinstalled in the model slope. Additionally, for each component of the model slope, samples were collected, and soil mechanics tests (i.e., cutting ring method, resonant column test, direct shear test, uniaxial compression test, and triaxial test) were performed to obtain the physical parameters. The mechanical parameters of the test model are presented in Table 3.
After the model slope was completed, the prestressed anchor cables and double-row antisliding piles were used to reinforce the slope through the reserved holes. Considered to be rigid, the antisliding piles were made of concrete with a section of $2.0 \mathrm{~cm}$ by $3.0 \mathrm{~cm}$, and the bending deformation of which were ignored in this work. As shown in Figure 4, a row of antisliding piles labeled the Pile A were installed at the waist of the model slope, and the other row of piles named the Pile B were located at the slope toe. The height of the Pile $A$ and $B$ are $20.0 \mathrm{~cm}$ and $16.0 \mathrm{~cm}$, respectively. Due to the limitation of the model size, it is difficult to install too many rows of prestressed anchor cables in the mode slope. It should be pointed out, in this work, the adjacent six rows of prestressed anchor cables are merged to be one row. Therefore, three rows of prestressed anchor cables numbered 1\#, 2\#, and 3\# were installed above the Pile A, as can be seen in Figure 4; the other four rows were installed between the Pile A and B, which were numbered with $4 \#, 5 \#, 6 \#$, and 7\#.

For the prestressed anchor cables, as presented in Figure 5(a), the construction holes were reserved using PVC pipes with diameter of $8.0 \mathrm{~cm}$. The prefabricated anchor cables were inserted into the reserved holes. Then, with pulling the PVC pipes out, the reserved holes were filled with sand simultaneously. The depth of sand was determined by the designed length of the anchorage segment of the anchor 
TABLE 2: Similarity ratios of the shaking table test.

\begin{tabular}{lcc}
\hline Parameters & Dimensions & Similarity ratio \\
\hline Physical dimension $(L)$ & {$[\mathrm{L}]$} & $C_{L}=100$ \\
Density $(\rho)$ & {$[\mathrm{M}][\mathrm{L}]^{-3}$} & $C_{\rho}=1$ \\
Acceleration $(a)$ & {$[\mathrm{L}][\mathrm{T}]^{-2}$} & $C_{a}=1$ \\
Elasticity modulus $(E)$ & {$[\mathrm{M}][\mathrm{L}]^{-1}[\mathrm{~T}]^{-2}$} & $C_{E}=100$ \\
Stress $(\sigma)$ & {$[\mathrm{M}][\mathrm{L}]^{-1}[\mathrm{~T}]^{-2}$} & $C_{\sigma}=100$ \\
Strain $(\varepsilon)$ & 1 & $C_{\varepsilon}=1$ \\
Force $(F)$ & {$[\mathrm{M}][\mathrm{L}][\mathrm{T}]^{-2}$} & $C_{F}=1000000$ \\
Velocity $(v)$ & {$[\mathrm{L}][\mathrm{T}]^{-1}$} & $C_{v}=10$ \\
Time $(t)$ & {$[\mathrm{T}]$} & $C_{t}=10$ \\
Displacement $(u)$ & {$[\mathrm{L}]$} & $C_{u}=100$ \\
Angular displacement $(\theta)$ & 1 & $C_{\theta}=1$ \\
Frequency $(\omega)$ & {$[\mathrm{T}]^{-1}$} & $C_{\omega}=0.1$ \\
Damping ratio $(\lambda)$ & 1 & $C_{\lambda}=1$ \\
Internal friction angle $(\varphi)$ & 1 & $C_{\varphi}=1$ \\
\hline \multicolumn{2}{l}{}
\end{tabular}

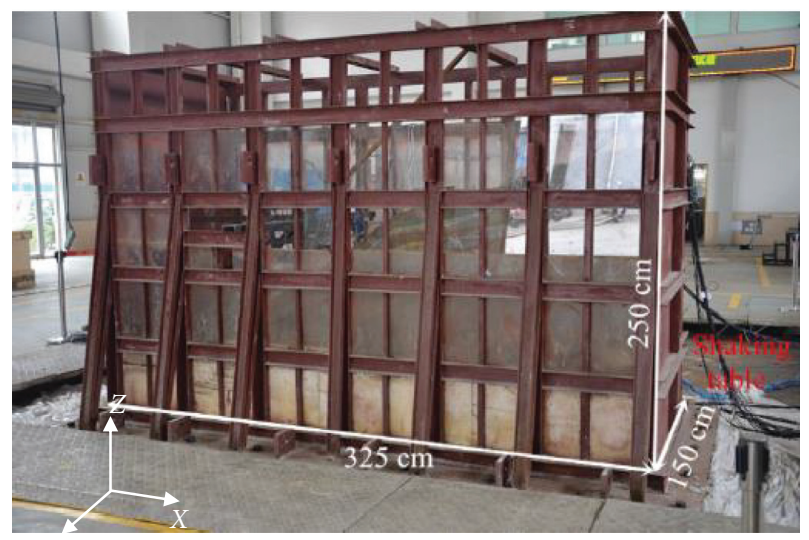

FIgURE 3: The rigid box container for the shaking table test.

cable. In this shaking table test, the length of the anchorage segment is $8.0 \mathrm{~cm}$. The cable material is steel with the diameter of $2.0 \mathrm{~cm}$. The inclined angle of the prestressed anchor cable is set to $20.0^{\circ}$. According to the designed pulling resistance and the similarity ratio, the filled sand in reserved holes was manually compacted for a given number of times, which was determined by the previous compaction test in the laboratory, as presented in Figure 5(d). The prestress of the anchor cable was applied by rotating the nut on the screw which was fixed on the lattice beam, and the applied prestress was close to real-time values measured by the axial force monitoring. It should be noted that utilizing the sand to fill the reserved holes does not seem to match the in situ field situation. However, by controlling and monitoring the prestress strictly, the specific physical significance of anchor cables in this shaking table test agrees well with that in the in situ field situation. In addition, to attenuate the wave reflection from the steel box during shaking, the expanded polystyrene boards with a thickness of $10.0 \mathrm{~cm}$ were placed between the slope model and test box $[18,19]$.

3.4. Sensor Layout. As shown in Figure 4, a total of 14 threedimensional accelerometers were installed inside the model slope and on the slope surface to measure accelerations in the horizontal and vertical directions. For the horizontal direction, the sensitivity of accelerometers is $173.46 \mathrm{mv} / \mathrm{g}$, which is $192.08 \mathrm{mv} / \mathrm{g}$ in the vertical direction. To measure the displacements on the slope surface, six laser displacement meters with the range of $30.00 \mathrm{~cm}$ were installed at different locations throughout the slope height, and the sensitivity of which was $33.33 \mathrm{mv} / \mathrm{mm}$. For the prestressed anchor cables, as shown in Figure 5(b), axial force sensors installed at the tension segment were employed to measure the axial force. The sensitivity of the axial force sensor was $1.50 \mathrm{mv} / \mathrm{v}$. Additionally, the dynamic earth pressure acting on the back of antisliding piles was measured by the earth pressure cells with the measuring range of $0.00 \mathrm{MPa} \sim 0.80 \mathrm{MPa}$. As illustrated in Figure 5(c), five earth pressure cells were installed on the Pile $B$ and numbered with $1 \# \sim 5 \#$; the other five ones for the Pile A were numbered with $6 \# \sim 10 \#$.

All the abovementioned sensors are new, and calibration of which was conducted before the shaking table test. Moreover, to attenuate the boundary effect on the test results, all the earth pressure cells and axial force sensors were installed on the middle column of antisliding piles and prestressed anchor cables, and all the accelerometers and laser displacement meters were also installed in the middle section.

3.5. Seismic Loadings and Shaking Sequence. The seismic loading used in this shaking table test was the El Centro earthquake record which has been widely used in the earthquake engineering. Two simultaneous loading directions of seismic excitations were applied in this shaking table test, namely, the $X$ and $Z$ direction, for which the corresponding time histories of the input seismic motions can be seen in Figure 6. Based on the similarity criteria, the input earthquake records were compressed in the time axis with a compression ratio of 10.00 (the similarity ratio of Time $t$ ). Six different horizontal peak accelerations of the input seismic loadings (i.e., $0.15 \mathrm{~g}, 0.30 \mathrm{~g}, 0.40 \mathrm{~g}, 0.50 \mathrm{~g}, 0.70 \mathrm{~g}$, and $0.90 \mathrm{~g}$ ) were selected. As highlighted in Refs. [20-22], the vertical peak acceleration is generally two-thirds of the horizontal peak acceleration. Additionally, before the excitation of the El Centro earthquake record, the model was scanned by the $0.05 \mathrm{~g}$ white noise. The loading sequence of the shaking table tests is listed in Table 4.

\section{Results and Discussions}

4.1. Acceleration Responses. The slope would have obvious nonlinear responses under strong seismic motions [23]. According to Ref. [24], the acceleration amplification behavior of the prototype slope could be well revealed by the shaking table test. In this study, the baseline corrected and band-pass filtered are adopted to the measured signals before calculating amplification factors. The peak values of horizontal accelerations are obtained by taking the maximum absolute values from the acceleration time histories.

In this section, the ratio of the peak horizontal acceleration obtained on the slope surface or inside the slope to 
TABle 3: Material parameters for the test model.

\begin{tabular}{|c|c|c|c|c|c|c|}
\hline \multicolumn{2}{|c|}{ Material } & Density $\rho\left(\mathrm{g} / \mathrm{cm}^{3}\right)$ & Elastic modulus $E(\mathrm{MPa})$ & Friction angle $\left({ }^{\circ}\right)$ & Cohesion $c\left(10^{-4} \mathrm{MPa}\right)$ & Poisson's ratio $\mu$ \\
\hline \multirow{2}{*}{ Slope } & M 1 & 2.50 & 9.80 & 40.00 & 6.00 & 0.25 \\
\hline & M 2 & 1.95 & 0.40 & 15.00 & 5.50 & 0.30 \\
\hline \multicolumn{2}{|c|}{ Rock base } & 2.70 & 10.10 & 42.00 & 7.40 & 0.25 \\
\hline \multicolumn{2}{|c|}{$\begin{array}{l}\text { Potential } \\
\text { sliding zone }\end{array}$} & 1.80 & $1.20 \times 10^{-2}$ & 12.00 & 0.75 & 0.25 \\
\hline \multicolumn{2}{|c|}{$\begin{array}{l}\text { Antisliding } \\
\text { pile }\end{array}$} & 2.70 & 301.00 & \multirow{2}{*}{\multicolumn{2}{|c|}{ Elastic material }} & 0.20 \\
\hline \multicolumn{2}{|c|}{$\begin{array}{l}\text { Anchorage } \\
\text { segment }\end{array}$} & 2.50 & 290.00 & & & 0.20 \\
\hline
\end{tabular}
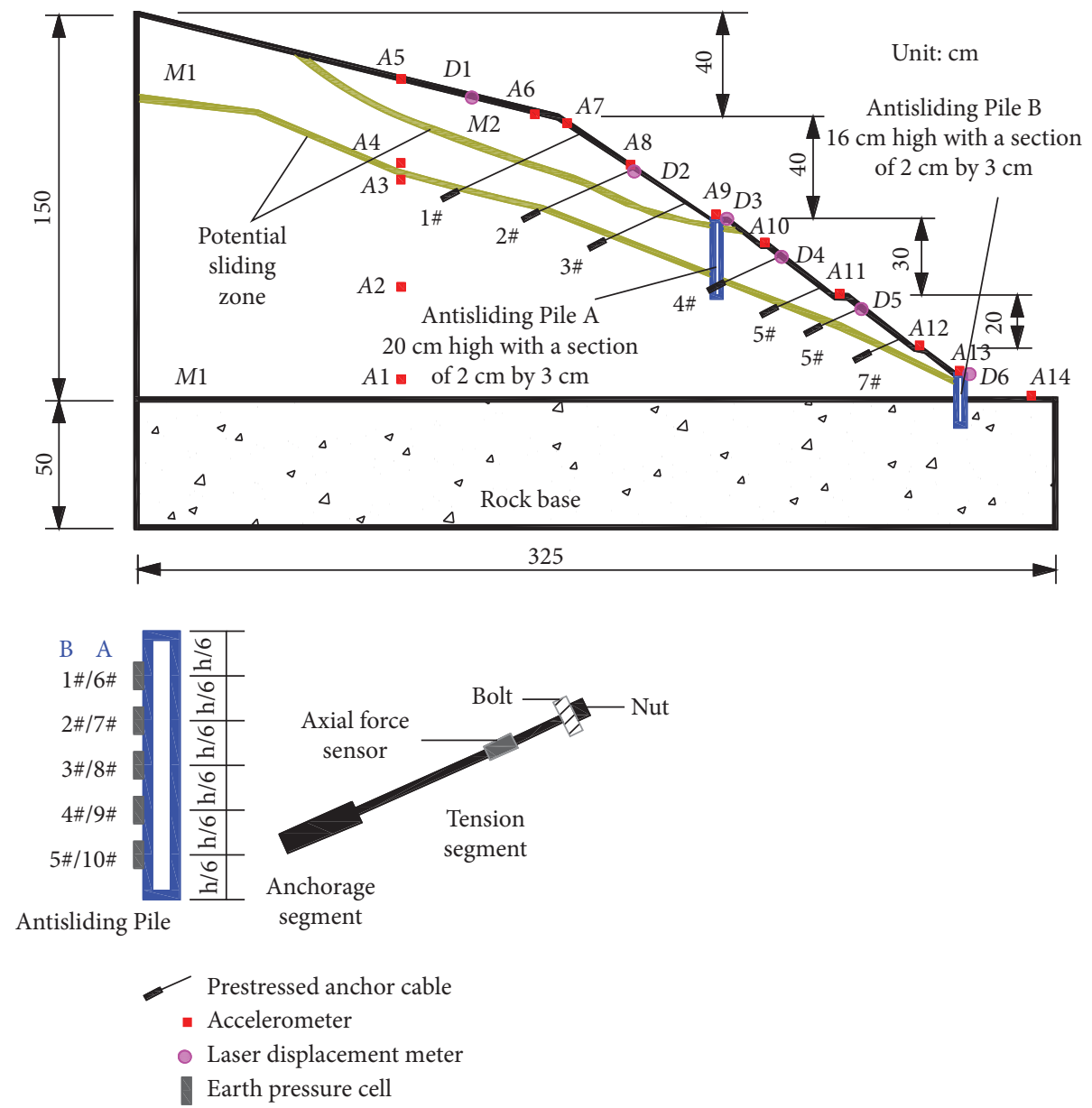

FIgURE 4: Layout of sensors and detailed views of the antisliding pile and prestressed anchor cable.

that collected by A14 is defined as the amplification factor. Figure 7 presents the variations of the amplification factor of horizontal acceleration on the slope surface and inside the slope. As shown in Figure 7(a), comparing with the slope mass above the Pile A, the amplification factors on the slope surface between the Pile A and B are smaller. This indicates that the existence of the Pile A weakens the seismic responses of the slope effectively. However, for the slope mass above $1 \#$ anchor cable, the acceleration amplification factor increases rapidly along the slope height because of the reason that this part of the slope is not reinforced by any supporting structures. Based on the above analysis, the prestressed anchor cables and double-row antisliding piles could effectively reduce the dynamic responses of the slope surface under earthquakes. It can be seen from Figure 7(b) that the amplification factor of horizontal acceleration inside the slope increases generally with the slope height, whereas the acceleration amplification factor decreases when the seismic waves pass through the potential sliding zone from the bottom to the top. It indicates that some of the energy carried by earthquake waves could be dissipated by the potential sliding zone. 


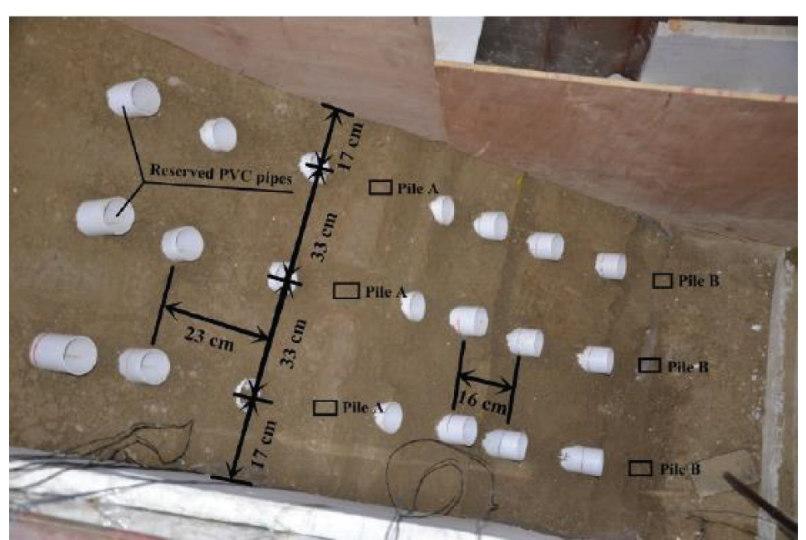

(a)

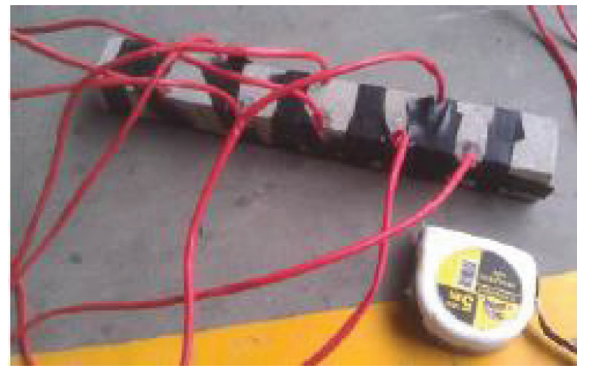

(c)

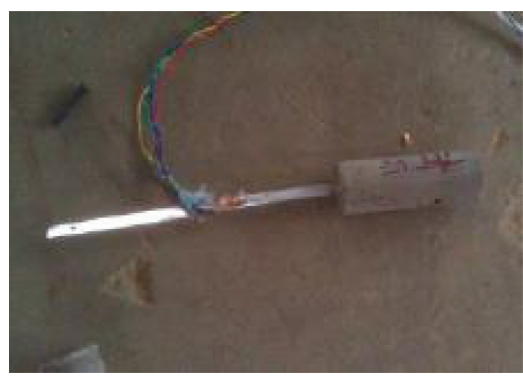

(b)

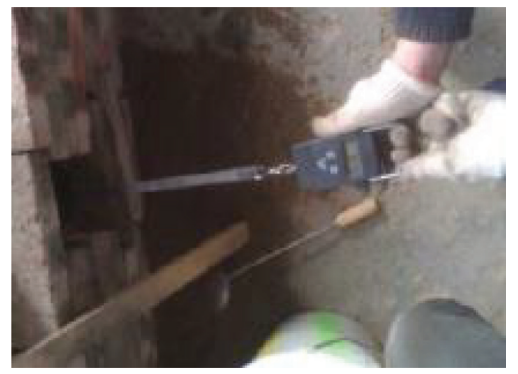

(d)

Figure 5: The model slope and the retaining structures. (a) Schematic diagram of the model slope. (b) Prestressed anchor cable. (c) Antisliding pile. (d) Compaction test for the anchor cable.

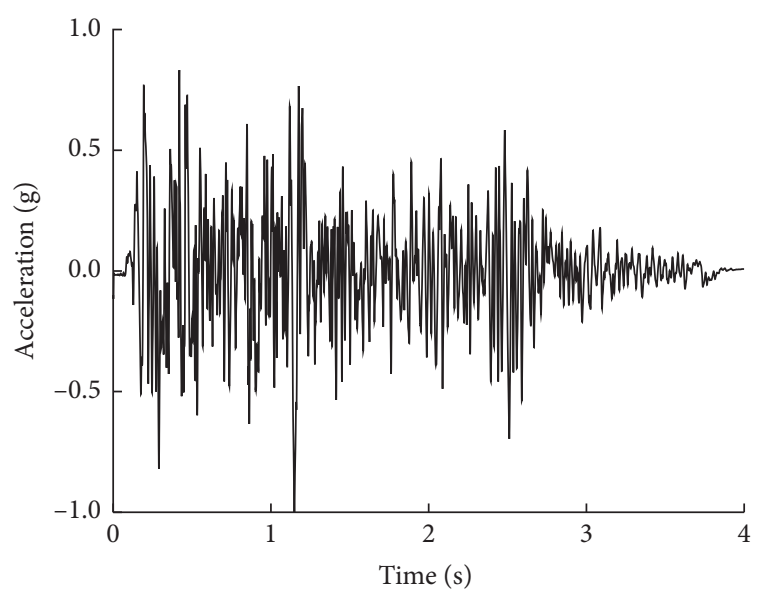

(a)

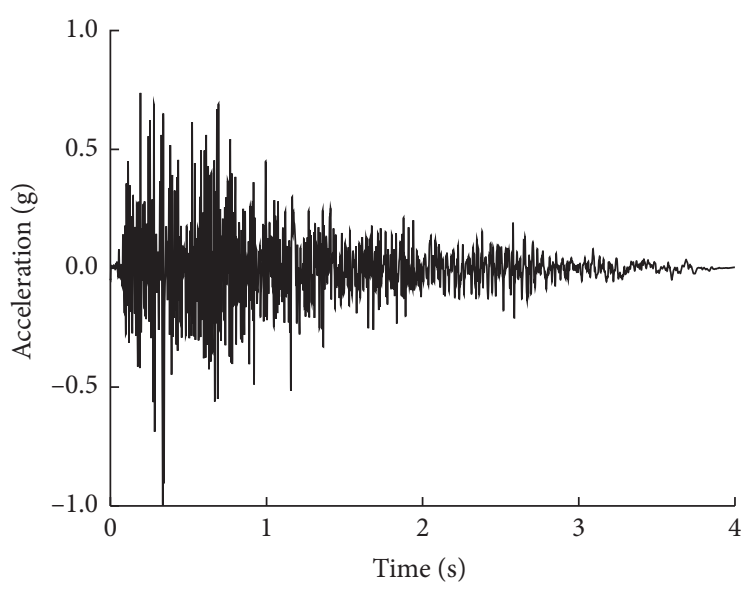

(b)

Figure 6: The input El Centro earthquake motions. (a) The horizontal seismic excitation. (b) The vertical seismic excitation.

4.2. Axial Force of the Prestressed Anchor Cables. To research the seismic responses of prestressed anchor cables, the axial force of each anchor cable was measured, and the initial values of which before each excitation are listed in Table 5. For 2\# prestressed anchor cable, the time histories of the axial force under the El Centro seismic loading with different amplitudes are plotted in Figure 8. From the figure, the variations of axial forces are similar to the time history of the input excitation (in Figure 6). The peak values of axial force occur at around the same time for that of the input earthquake motion. In this work, to well discuss the seismic responses of the prestressed anchor cables, the peak values and residual values of the axial force are analyzed separately.

4.2.1. Peak Values of the Axial Force. Figure 9 shows that the peak values of the axial force of prestressed anchor cables increase with the amplitudes of the input seismic loadings, especially when the input amplitude is larger than $0.5 \mathrm{~g}$. It 
TABLE 4: Loading sequence for the shaking table test.

\begin{tabular}{llc}
\hline No. & Seismic input & Amplitude $(\mathrm{g})$ \\
\hline 1 & White noise & 0.05 \\
2 & El Centro wave & 0.15 \\
3 & El Centro wave & 0.30 \\
4 & El Centro wave & 0.40 \\
5 & El Centro wave & 0.50 \\
6 & El Centro wave & 0.70 \\
7 & El Centro wave & 0.90 \\
\hline
\end{tabular}

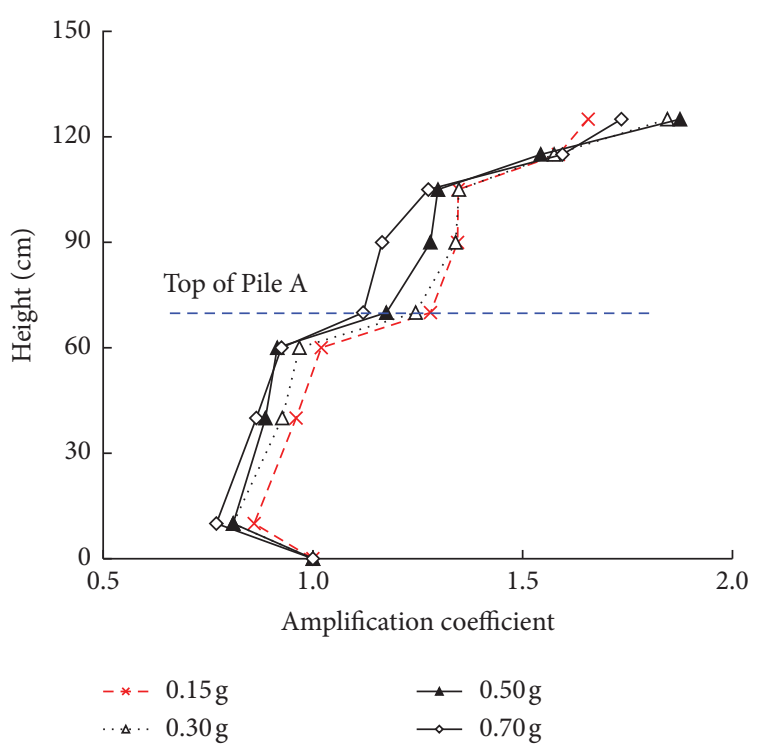

(a)

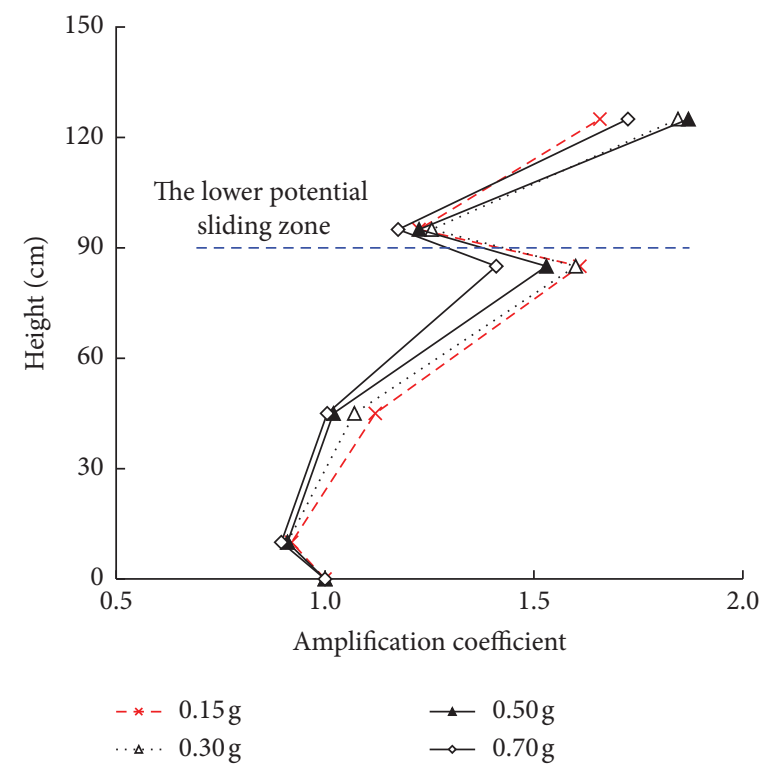

(b)

Figure 7: Amplification factors of the horizontal acceleration. (a) At the slope surface. (b) Inside the slope.

TABLE 5: Initial prestress values of the prestressed anchor cables before each seismic excitation (Unit: N).

\begin{tabular}{lllllll}
\hline \multirow{2}{*}{ No. } & \multicolumn{7}{c}{ Amplitude } \\
& $0.15 \mathrm{~g}$ & $0.30 \mathrm{~g}$ & $0.40 \mathrm{~g}$ & $0.50 \mathrm{~g}$ & $0.70 \mathrm{~g}$ & $0.90 \mathrm{~g}$ \\
\hline 1 & 35.20 & 30.60 & 30.90 & 30.80 & 27.50 & 24.10 \\
2 & 26.50 & 21.40 & 22.50 & 22.40 & 20.70 & 17.80 \\
3 & 25.40 & 19.20 & 20.70 & 20.90 & 20.40 & 18.60 \\
4 & 22.70 & 18.50 & 19.00 & 21.10 & 21.60 & 19.80 \\
5 & 16.10 & 10.20 & 10.60 & 12.00 & 13.50 & 14.30 \\
6 & 23.50 & 18.40 & 17.60 & 18.40 & 18.60 & 18.30 \\
7 & 17.60 & 17.00 & 18.60 & 18.20 & 20.10 & 22.00 \\
\hline
\end{tabular}

indicates that the performance of the anchor cable is taken full advantage when the amplitude of excitation is greater than $0.5 \mathrm{~g}$. As presented in Figure 4, seven rows of prestressed anchor cables can be divided into two parts by the Pile A. The maximum increment of the axial force occurs in 2\# prestressed anchor cable. The increment of the peak axial force of $1 \#$ anchor cable is larger than that of $3 \#$ anchor cable, especially when the input amplitude of seismic motion is larger than $0.4 \mathrm{~g}$. It indicates that stronger dynamic responses occur on the upper part of the slope. Under earthquake loadings, the sliding force is firstly undertaken by the anchor cables located in the upper part of the slope, and the rest of which is undertaken by other anchor cables. For the prestressed anchor cables located between the Pile A and $B$, the increment of the peak axial force increases generally with the slope height. However, the increment of the peak axial force in $7 \#$ anchor cable is larger than $5 \#$ and 6\# anchor cables and smaller than $4 \#$ anchor cable. This is due to that, with a shorter free segment, the seismic responses of the axial force of $7 \#$ anchor cable are mainly influenced by the anchor cable length.

To further reveal the relationship between the initial axial force and the variation of axial force during shaking, the notation $\alpha$ is defined in this section as the increase rate of axial force, which is expressed as follows:

$$
\alpha=\frac{\left(A_{2}-A_{1}\right)}{A_{1}}
$$

where $A_{1}$ is the initial axial force of the anchor cable and $A_{2}$ denotes the peak value of axial force during earthquake loadings.

The increase rates of the axial force of anchor cables under the El Centro earthquake motions with different amplitudes are depicted in Figure 10. It can be seen from the figure that, under $0.50 \mathrm{~g}, 0.70 \mathrm{~g}$, and $0.90 \mathrm{~g}$ seismic 


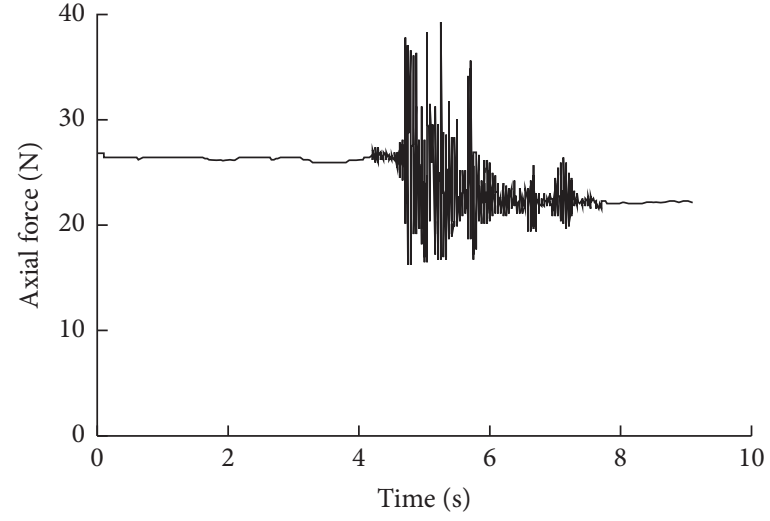

(a)

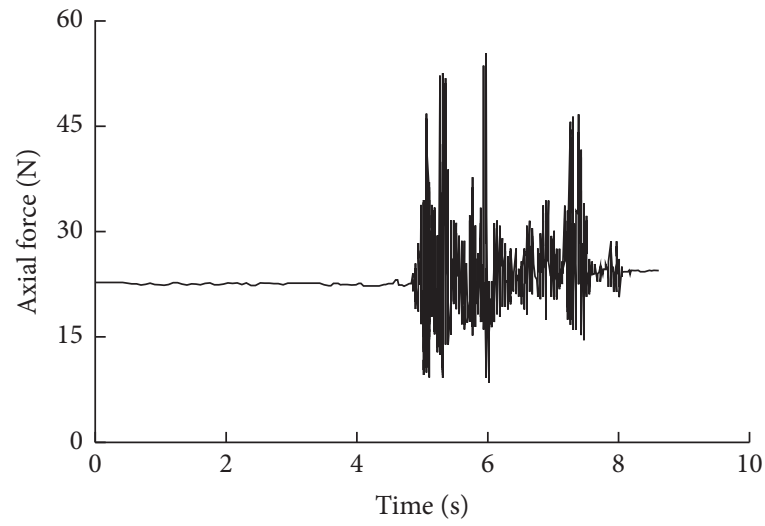

(c)

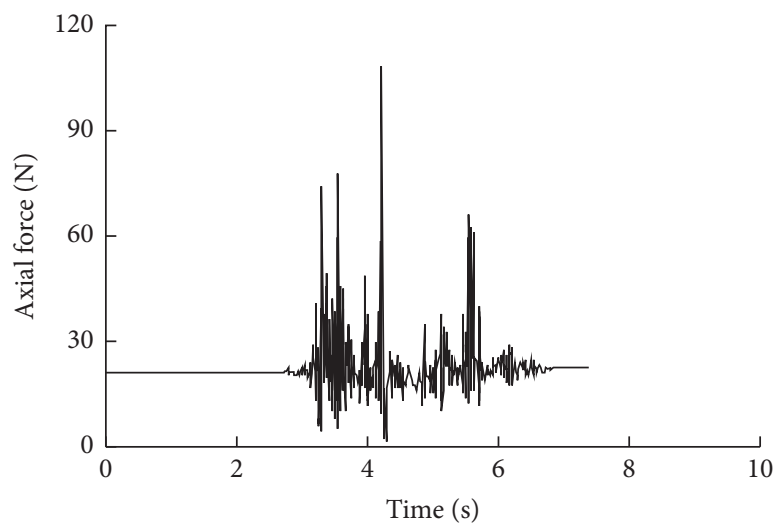

(e)

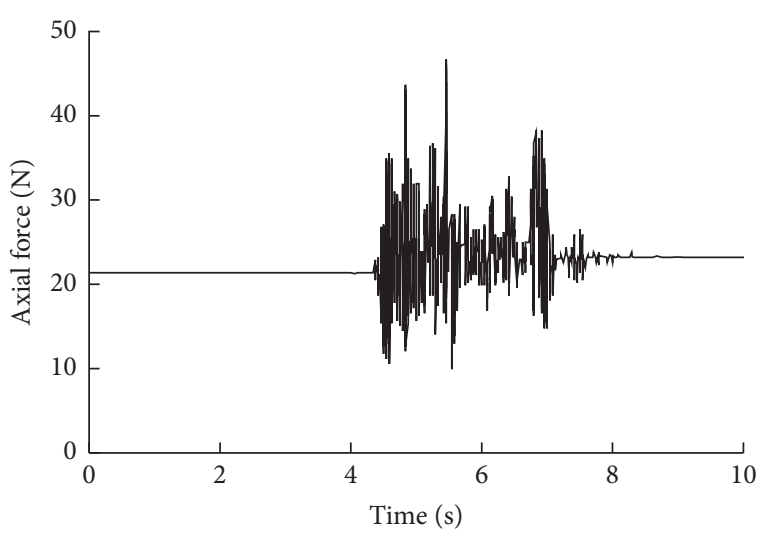

(b)

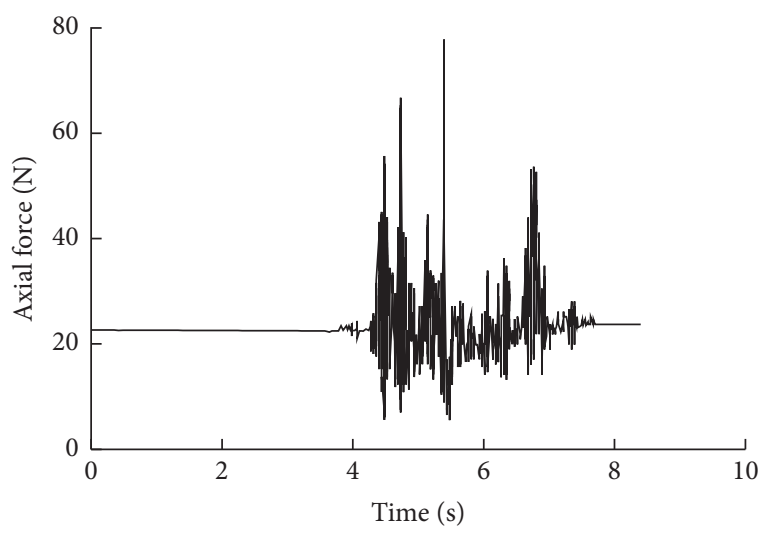

(d)

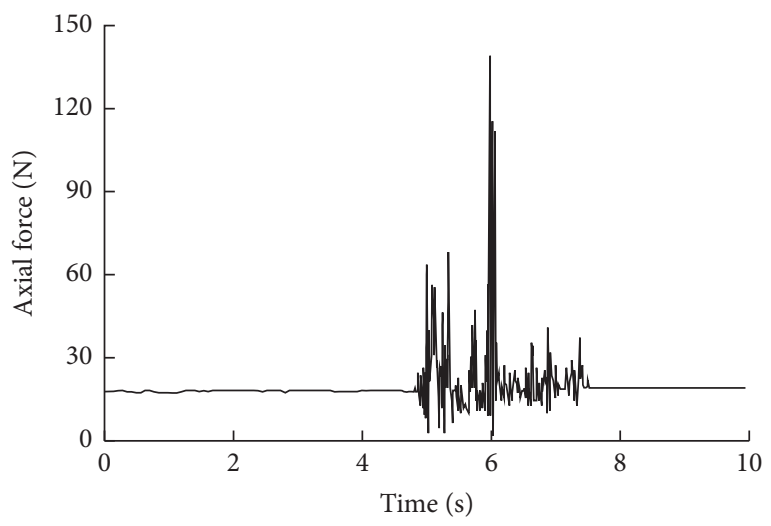

(f)

FIGURE 8: Time histories of 2\# anchor cable under seismic motions with the amplitude of (a) $0.15 \mathrm{~g}$; (b) $0.30 \mathrm{~g}$; (c) $0.40 \mathrm{~g}$; (d) $0.50 \mathrm{~g}$; (e) $0.70 \mathrm{~g}$; (f) $0.90 \mathrm{~g}$.

excitations, the increase rates of axial force for $2 \#$ anchor cable are $2.49,4.22$, and 6.79 , respectively, which is the maximum among the prestressed anchor cables. For the other anchor cables, the increase rates are smaller than 2.00 when the amplitude of earthquake loading is not larger than $0.70 \mathrm{~g}$, and in the range of $0.83 \sim 3.30$ under $0.90 \mathrm{~g}$ seismic motions. In reference to the current seismic design method, the safety factor of the calculation of the section area for the prestressed anchor cable is 2.20 , in which only static condition is considered. It can be highlighted that the performance of the prestressed anchor cable under dynamic conditions should be taken into consideration in the seismic design.

The occurrence time of the peak axial force for seven prestressed anchor cables under different excitations is shown in Figure 11. To ensure the integrity of the data collected in the shaking table tests, the data acquisition starts some time before the input of each excitation. Therefore, it is meaningless to compare the occurrence time of the peak axial force with time history of the input 


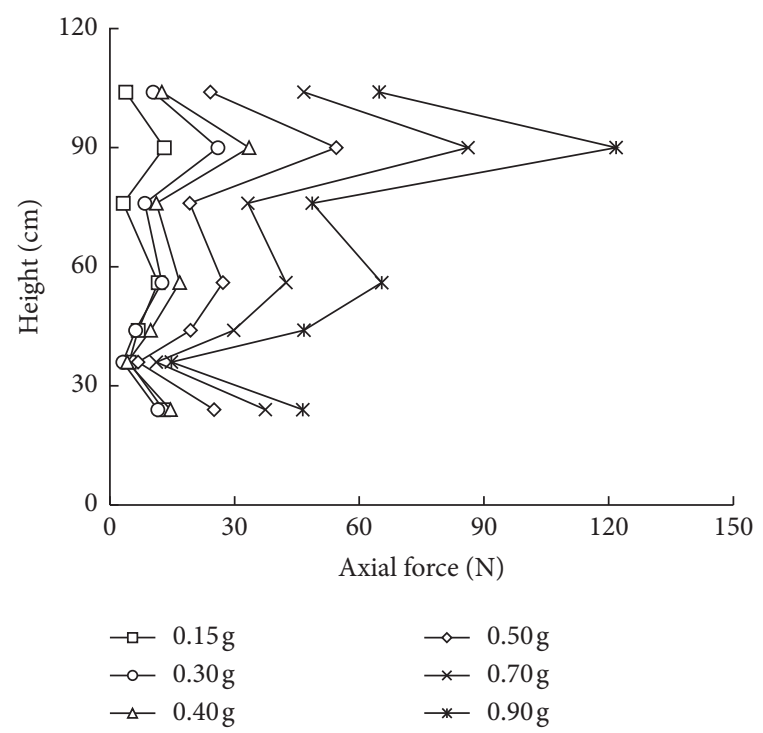

Figure 9: Distribution of the peak axial force for all seven anchor cables under seismic motions with different amplitudes.

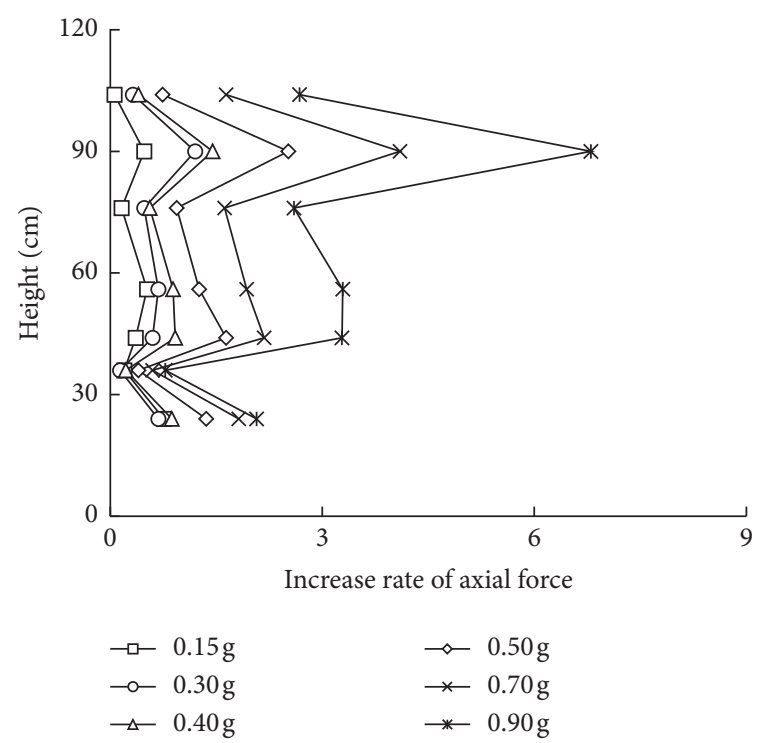

FIGURE 10: Variations of the increase rate of axial force under seismic motions with different amplitudes.

El Centro seismic motion, and the comparison of the occurrence time of peak axial force between different prestressed anchor cables would be discussed in this work. It can be seen from Figure 11 that the most anchor cables get their peak vibration values almost at the same time under each seismic excitation, which indicates that all the prestressed anchor cables work together during shaking. However, under $0.15 \mathrm{~g}$ earthquake motion, the occurrence time of the peak axial force for the anchor cables located in the upper part of the slope is somewhat earlier than those in the lower part. This is mainly because that the slope mass is compacted during the seismic excitations, which affects the propagation of the earthquake wave in the slope.

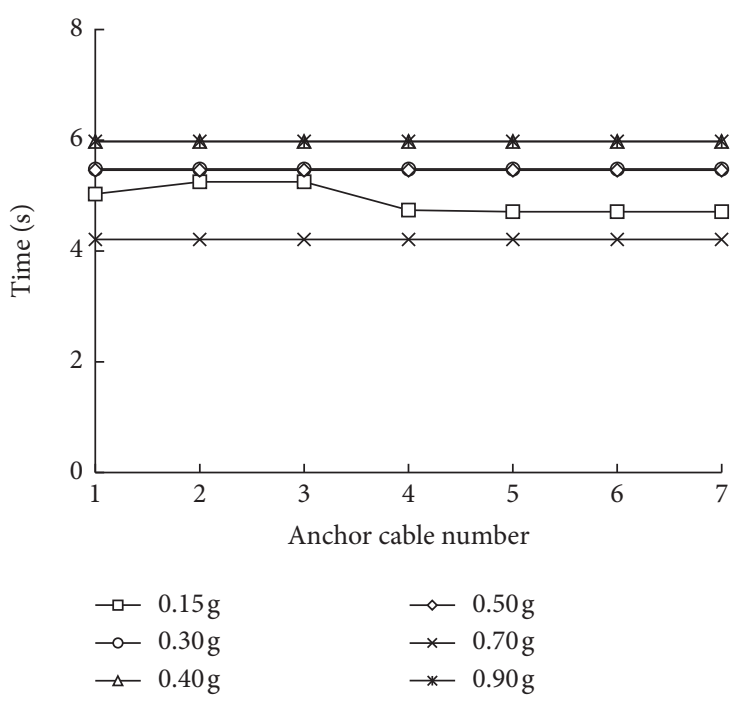

Figure 11: The occurrence time of the peak axial force of all seven anchor cables.

4.2.2. Residual Values of Axial Force. For the seismic design of the prestressed anchor cable, the prestress loss and the residual value of axial force after earthquake are of great significance. In this work, the notation $\beta$ is defined as the changing rate of axial force, which is expressed as

$$
\beta=\frac{\left(A_{3}-A_{1}\right)}{A_{1}},
$$

in which $A_{1}$ is the initial axial force of the anchor cable and $A_{3}$ denotes the residual value of axial force after each seismic excitation.

The changing rates of axial force for each anchor cable under seismic excitations are presented in Figure 12. When subjected to $0.15 \mathrm{~g}$ seismic motions, the loss of prestress for $1 \#$, 2\#, and 3\# anchor cables are $11.00 \%, 16.00 \%$, and $22.00 \%$, respectively. Under the excitations with amplitudes in the range of $0.30 \mathrm{~g} \sim 0.70 \mathrm{~g}$, the prestress of $1 \#$ anchor cable is lost by $4.00 \%$ approximately, and by $21.00 \%$ under $0.90 \mathrm{~g}$ seismic motion. Both for 2\# and 3\# anchor cables, the prestress increases under $0.30 \mathrm{~g} \sim 0.90 \mathrm{~g}$ seismic excitations. The maximum increment of prestress in 2\# anchor cable is about $10.00 \%$, which is greater than that in $3 \#$ anchor cable. The loss of prestress for $4 \#, 5 \#$, and $6 \#$ anchor cables are $21.00 \%$, $23.00 \%$, and $19.00 \%$ under $0.15 \mathrm{~g}$ earthquake excitation, whereas there is almost no prestress loss in $7 \#$ anchor cable. When subjected to $0.30 \mathrm{~g}$ excitation, the residual axial forces of prestressed anchor cables between the Pile A and B are mainly identical with the initial values. In addition, under the seismic motions with other amplitudes, the prestress of these four anchor cables increases about $10.00 \%$. According to the analysis above, since the maximum of prestress loss is about $23.00 \%$ in this test, it is suggested that the initial axial force of the prestressed anchor cable could be raised by 1.20 1.30 times in the seismic design.

The test results show that the axial forces of the prestressed anchor cables in different slope areas are significantly different. It indicates that, for the current seismic 


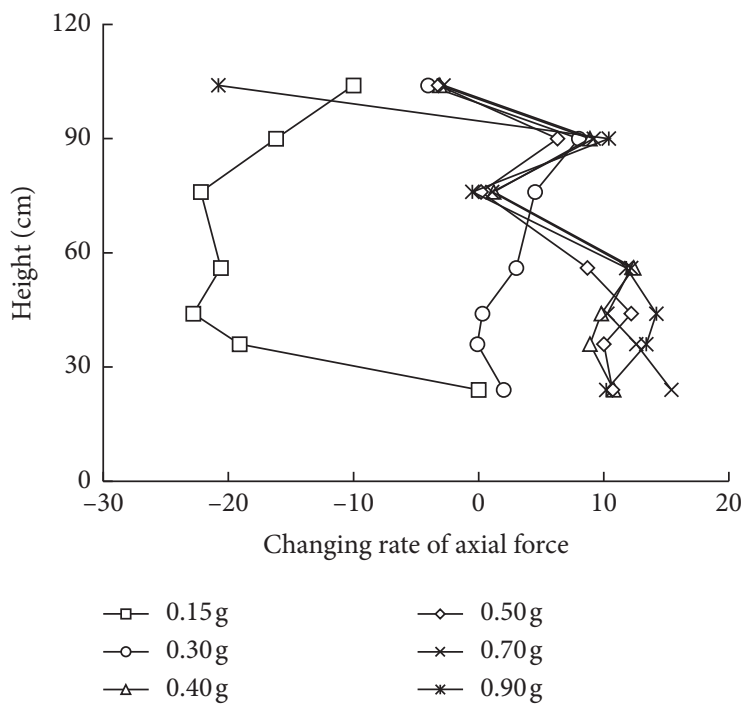

FIGURE 12: Variations of the changing rate of axial force under seismic motions with different amplitudes.

design method, all the prestressed anchor cables are assumed to sustain the same load is inaccurate and uneconomic. In practice, the failure of one anchor cable can cause the failures of adjacent ones because of the chain reaction, which could lead to the slope failure. Therefore, the seismic response differences between anchor cables located in different areas should be fully taken into consideration in the seismic design. Additionally, to ensure the reliability of the prestressed anchor cables and the slope stability, specific design considerations should be adopted in the areas with different geological conditions.

4.3. Lateral earth Pressure on the Antisliding Piles. The lateral earth pressures acting on the back of the antisliding Pile A and $\mathrm{B}$ under the excitations of El Centro earthquakes are shown in Figure 13. It should be noted that the lateral earth pressure plotted in Figure 13 is the dynamic earth, and the static pressure is not considered in this section. Both for the Pile A and B, the lateral earth pressure increases with the increasing input amplitude. Comparing with the Pile $A$, the lateral earth pressure acting on the back of the Pile B is much greater, especially for the location with relative height of 0.17 and 0.50 . Under the excitations with the amplitude of $0.15 \mathrm{~g}$ and $0.30 \mathrm{~g}$, the distribution curves of earth pressure acting on the Pile A are similar to the Pile B. However, when the input amplitude becomes larger than $0.50 \mathrm{~g}$, the lateral earth pressure acting on the Pile A decreases first and then increases along the height, and the minimum of which occurs near the location with relative height of 0.67 . It can be seen from Figure 14(b), for the Pile A, the earth pressure acting on the pile toe is larger than that acting on the pile top. As highlighted in Reference [25], the earth pressure measured behind the piles can be equivalent to the earth pressure used in the traditional pseudostatic design, due to the piles are assumed to be rigid. Hence, the major cause of this phenomenon is that the plastic strain happens in the surrounding soil near the top and toe of the pile under strong earthquake motions. Note that, comparing with the soils, the model piles in this test are of infinite strength and stiffness, leading to rigid rotation and translation of piles during seismic loading. In addition, the difference of the distribution of earth pressure between the Pile A and B is mainly contributed that the Pile B is embedded much deeper than the Pile A and behaving nearly as a fixed pile.

For the seismic responses of double-row antisliding piles, few studies were related to the load-sharing ratio. The ratios between the peak lateral earth pressure acting on the back of the Pile B and A are depicted in Figure 14. It can be seen from the figure that the ratios change mainly in the range of 2.0 5.0, implying that there is a large difference on the load-sharing ratios between the Pile A and B. The earth pressure acting on the back of the Pile $B$ is much larger than that of the Pile A. As highlighted in Refs. $[15,26]$, the seismic design intensity scale of most areas in China is not larger than 9.0, and the corresponding design acceleration of which is smaller than $0.4 \mathrm{~g}$. The test results in this work have an important practical significance for China and also can provide a reference for other countries and regions in the world.

4.4. Horizontal Displacements on the Slope Surface. The horizontal displacements on the slope surface were measured by the laser displacement meters located at different locations throughout the slope height. In this work, the horizontal displacement towards the slope is defined as negative and that away from the slope is defined as positive. In Figure 15, the peak horizontal displacements during seismic excitations and the postearthquake permanent displacements are presented. The figure shows that, when the input amplitude is not larger than $0.50 \mathrm{~g}$, the permanent lateral displacements on the slope surface are small which indicates that the reinforced slope is of good overall stability. 


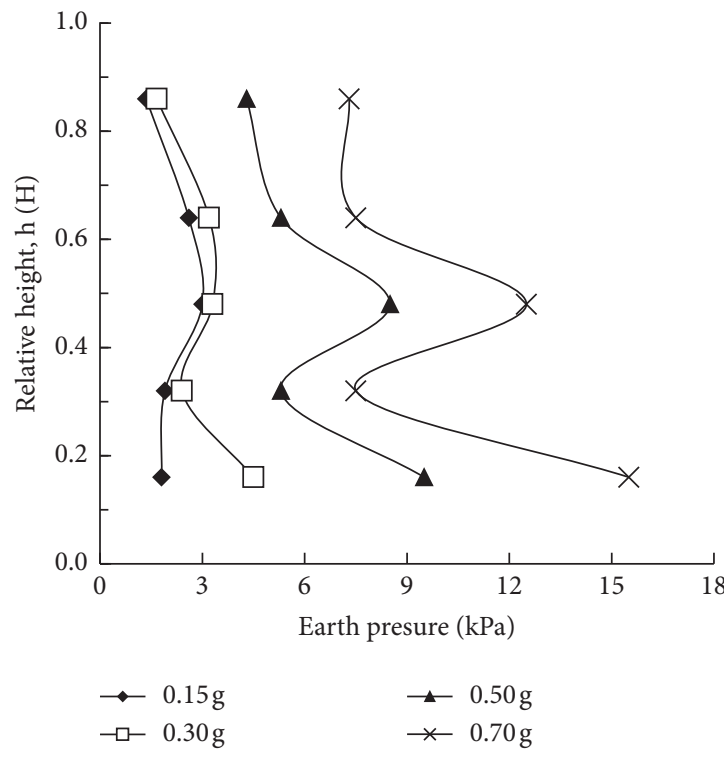

(a)

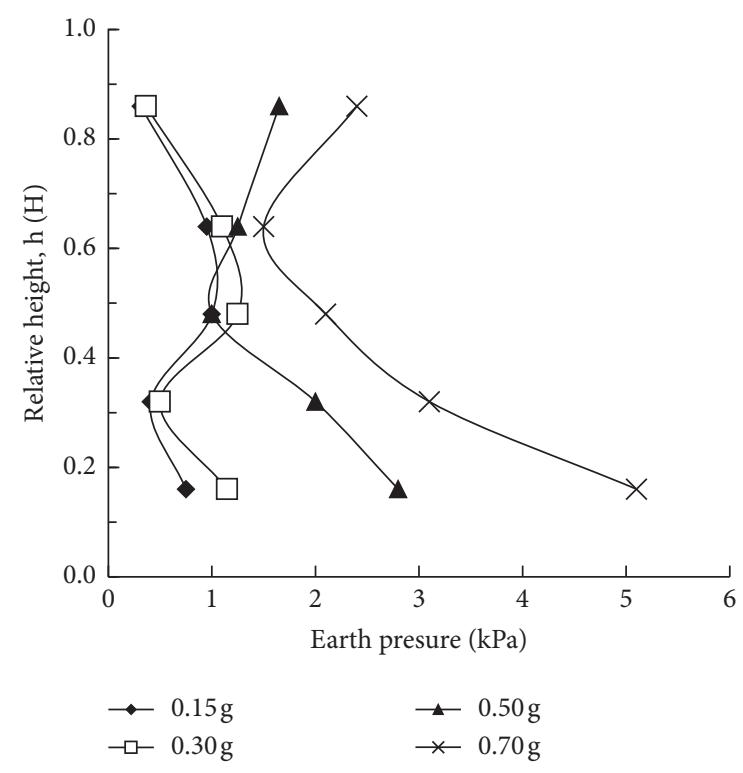

(b)

FIgURE 13: Lateral earth pressure acting on the back of (a) the pile B and (b) Pile A under the El Centro earthquake excitations.

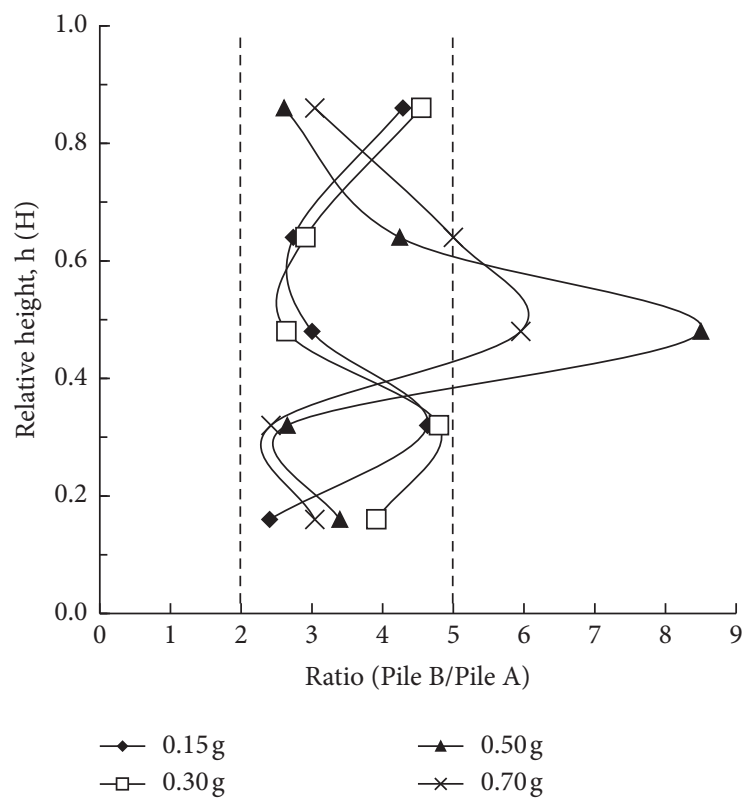

FIgURE 14: The load-sharing ratios between the pile B and A under El Centro earthquake motions.

The peak displacement and permanent displacement on the slope surface increase with the increasing amplitude of the input seismic motions. The slope could be divided into two parts by the Pile A, and the horizontal displacements on the slope surface both for the upper and lower parts of the slope increase with the elevation. Additionally, it should be noted that the negative permanent displacements on the slope surface occur under $0.15 \mathrm{~g}$ El Centro earthquake motion. It is mainly because of that the slope mass is compacted somewhat under the dual actions of seismic motion and 


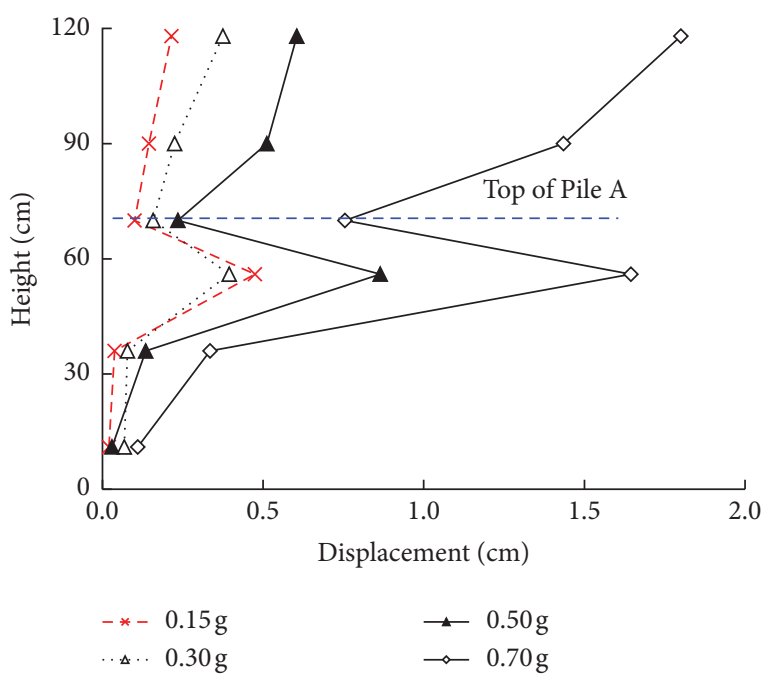

(a)

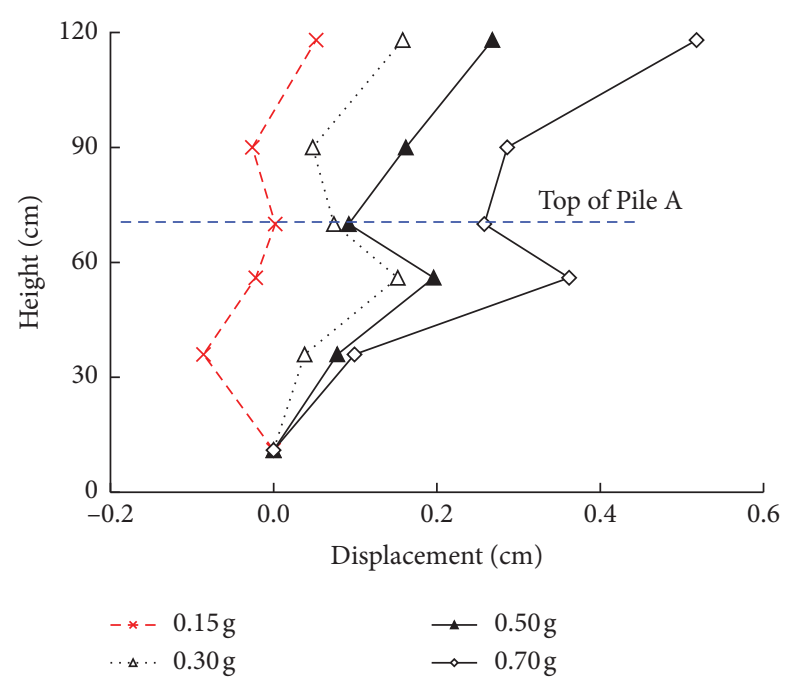

(b)

Figure 15: Horizontal displacements on the slope surface under the excitations of El Centro earthquake motion. (a) Peak displacement, (b) Permanent displacement.

retaining structures, and this phenomenon is in accordance with the prestress loss of anchor cables under $0.15 \mathrm{~g}$ seismic motion.

\section{Conclusions}

According to the test results, several conclusions can be drawn:

(1) Comparing with the unreinforced part of the slope, the value and the increase rate of the acceleration amplification factor can be effectively controlled by the reinforcements of prestressed anchor cables and double-row antisliding piles, especially for the slope mass between the Pile A and B.

(2) The maximum of prestress loss is $23.00 \%$. When subjected $0.30 \mathrm{~g} \sim 0.90 \mathrm{~g}$ excitations, the maximum increment of axial force is $15.00 \%$. It can be highlighted that the initial prestress of the anchor cable is suggested to be raised by 1.20 1.30 times in the seismic design for the slope with high requirements of deformation control.

(3) The lateral earth pressures acting on the back of the Pile A and B increase with the increasing amplitude of the input seismic motions. Comparing with the Pile B located at the slope toe, the earthquake loading undertaken by the Pile A located at the slope waist is obviously smaller, and the load-sharing ratios between the Pile A and B mainly changed in the range of $2.0 \sim 5.0$.

(4) Under the seismic excitations, especially the input amplitude not larger than $0.5 \mathrm{~g}$, the lateral displacements on the slope surface can be controlled by the combined retaining structures well. It can be concluded that, reinforced by prestressed anchor cables and double-row antisliding piles, the slope would have a good overall stability.

\section{Data Availability}

The data used to support the findings of this study are available from the corresponding author upon request.

\section{Conflicts of Interest}

The authors declare that they have no conflicts of interest.

\section{Acknowledgments}

This work was supported by the National Natural Science Foundation of China (Grant no. 51808466) and Young Talents' Science and Technology Innovation Project of Hainan Association for Science and Technology (QCXM201807).

\section{References}

[1] G. Behrouz, J. A. Danial, and H. Mohsen, "Prediction of seismic slope stability through combination of particle swarm optimization and neural network," Engineering with Computers, vol. 32, pp. 85-97, 2016.

[2] H. B. Seed and R. V. Whitman, "Design of retaining structures for dynamic loads," in Proceedings of the ASCE Specialty Conference Lateral Stress In the Ground and Design of Earth Retaining Structures, pp. 103-145, Ithaca, NY, USA, June 1970.

[3] M. Kamon, T. Wako, K. Isemura et al., "Geotechnical disasters on the waterfront," Soils and Foundations, vol. 36, pp. 137147, 1996.

[4] J. Lai, Y. R. Zheng, Y. Liu, and X. D. Li, "Shaking table tests on double-row anti-slide piles of slopes under earthquakes," Chinese Journal of Geotechnical Engineering, vol. 36, no. 4, pp. 680-686, 2014. 
[5] L. W. Jiang, L. K. Yao, Z. X. Hu, and Q. H. Yang, "Experimental study on slope's superficial dynamic efect and anchoring prevention mechanism under earthquake disturbance," Journal of Sichuan University (Engineering Science Edition), vol. 42, no. 5, pp. 164-174, 2010.

[6] H. L. Ye, Y. Y. Zheng, A. H. Li, and X. L. Du, "Shaking table test studies of prestressed anchor cable of slope under earthquake," Chinese Journal of Rock Mechanics and Engineering, vol. 31, no. S1, pp. 2847-2854, 2012.

[7] Y.-1. Lin, Y.-X. Li, G.-l. Yang, and Y. Li, "Experimental and numerical study on the seismic behavior of anchoring frame beam supporting soil slope on rock mass," Soil Dynamics and Earthquake Engineering, vol. 98, pp. 12-23, 2017.

[8] D. Zheng, F.-z. Liu, N.-p. Ju, J. D. Frost, and R.-q. Huang, "Cyclic load testing of pre-stressed rock anchors for slope stabilization," Journal of Mountain Science, vol. 13, no. 1, pp. 126-136, 2016.

[9] M. Xu, Y. Tang, X. Liu, H. Yang, and B. Luo, "A shaking table model test on a rock slope anchored with adaptive anchor cables," International Journal of Rock Mechanics and Mining Sciences, vol. 112, pp. 201-208, 2018.

[10] N. Ma, H. Wu, H. Ma, X. Wu, and G. Wang, "Examining dynamic soil pressures and the effectiveness of different pile structures inside reinforced slopes using shaking table tests," Soil Dynamics and Earthquake Engineering, vol. 116, pp. 293-303, 2019.

[11] G. Ding, L. Zhou, J. Wang, Y. Xu, X. Geng, and X. Li, "Shaking table tests on gravel slopes reinforced by concrete canvas," Geotextiles and Geomembranes, vol. 48, no. 4, pp. 539-545, 2020.

[12] D. P. Zhou, J. J. Zhang, and Y. Tang, "Seismic damage analysis of road slopes in Wenchuan earthquake," Chinese Journal of Geotechnical Engineering, vol. 29, no. 3, pp. 565-576, 2010.

[13] Y. L. Lin, G. L. Yang, and X. Yang, "Response of gravity retaining wall with anchoring frame beam supporting a steep rock slope subjected to earthquake loading," Soil Dynamics and Earthquake Engineering, vol. 92, pp. 622-649, 2017.

[14] G. Fan, J.-j. Zhang, S.-c. Qi, and J.-b. Wu, "Dynamic response of a slope reinforced by double-row anti-sliding piles and prestressed anchor cables," Journal of Mountain Science, vol. 16, no. 1, pp. 226-241, 2019.

[15] General Administration of Quality Supervision, "Inspection and quarantine of the People's Republic of China \& standardization administration of People's Republic of China," Seismic Ground Motion Parameters Zonation Map of China (GB 18308-2015), General Administration of Quality Supervision, Beijing, China, 2015.

[16] E. Buckingham, "On physically similar systems; illustrations of the use of dimensional equations," Physical Review, vol. 4, no. 4, pp. 345-376, 1914.

[17] G. Fan, J. Zhang, J. Wu, and K. Yan, "Dynamic response and dynamic failure mode of a weak intercalated rock slope using a shaking table," Rock Mechanics and Rock Engineering, vol. 49, no. 8, pp. 3243-3256, 2016.

[18] R. J. Bathurst, S. Gaskin, and A. Gaskinc, "Shaking table testing of geofoam seismic buffers," Soil Dynamics and Earthquake Engineering, vol. 27, no. 4, pp. 324-332, 2007.

[19] M.-f. Lei, B.-c. Zhou, Y.-x. Lin, F.-d. Chen, C.-h. Shi, and L.-m. Peng, "Model test to investigate reasonable reactive artificial boundary in shaking table test with a rigid container," Journal of Central South University, vol. 27, no. 1, pp. 210-220, 2020.
[20] N. N. Ambraseys and J. Douglas, "Near-field horizontal and vertical earthquake ground motions," Soil Dynamics and Earthquake Engineering, vol. 23, no. 1, pp. 1-18, 2003.

[21] Z. H. Wang, T. Su, H. Konietzky, Y. L. Tan, and G. L. Zhou, "Hydraulic properties of Beishan granite after different high temperature treatments," Bulletin of Engineering Geology and the Environment, vol. 80, no. 4, pp. 2911-2923, 2021.

[22] N. P. Theodulidis and P.-Y. Bard, "Horizontal to vertical spectral ratio and geological conditions: an analysis of strong motion data from Greece and Taiwan (SMART-1)," Soil Dynamics and Earthquake Engineering, vol. 14, no. 3, pp. 177-197, 1995.

[23] H.-x. Liu, Q. Xu, and Y.-r. Li, "Effect of lithology and structure on seismic response of steep slope in a shaking table test," Journal of Mountain Science, vol. 11, no. 2, pp. 371-383, 2014.

[24] M.-L. Lin and K.-L. Wang, "Seismic slope behavior in a largescale shaking table model test," Engineering Geology, vol. 86, no. 2-3, pp. 118-133, 2006.

[25] H. I. Ling, Y. Mohri, D. Leshchinsky, C. Burke, K. Matsushima, and H. Liu, "Large-scale shaking table tests on modular-block reinforced soil retaining walls," Journal of Geotechnical and Geoenvironmental Engineering, vol. 131, no. 4, pp. 465-476, 2005.

[26] Ministry of Housing and Urban-Rural Development of the People's Republic of China, Code for Seismic Design of Building (GB50011-2010), Ministry of Housing and UrbanRural Development, Beijing, China, 2010. 